DISCUSIÓN

\title{
Estar-en-el-mundo trabajando: finitud, existencia y capitalismo actual
}

\section{Be-in-the-world working: finitude, existence and current capitalism}

\author{
Gabriela Martínez Ortiz \\ Universidad Autónoma de Aguascalientes \\ gabymo385@hotmail.com
}

\section{Resumen}

¿Qué significa estar-en-el-mundo dentro de una sociedad capitalista hiperconsumista? La relación entre trabajo y capital configura a la condición humana desde un modo de vincularse con el medio ambiente, con lo social, los otros y consigo mismo, mediado por el tipo de trabajo que realiza el individuo y por el lugar específico que esto lo hace ocupar en el mundo social. En este sentido, las subjetividades dadas en el régimen neoliberal parecieran limitarse a ser subjetividades que están en el mundo 
para trabajar, por lo que la relación entre trabajo y existencia requiere replantearse a partir de una ontología relacionada con sus condiciones materiales, históricas, culturales y sociales para encontrar otras formas de producir y reproducir la vida humana.

Palabras clave: trabajo, capitalismo, existencia.

\section{Abstract}

What does it mean be-in-the world within an hiper-consumerist capitalist society? Relation between work and capital configure human condition from a manner to be linked to environment, to the social, the others and to one self. And this manner is conditioned to the kind of work carry out by individuals, and to the position it makes her take in social world. In this sense, the subjectivities in neoliberal regime seems to be restricted to be in the world only to work. That is why the relation between work and existence require a reconsideration from an ontology related with the material, historical, cultural and social conditions, looking for other ways for produce and reproduce human life.

Key words: work, capitalism, existence.

\section{Introducción}

A partir de la segunda mitad siglo $X X$, el desenvolvimiento del capitalismo hacia sus fases neoliberales, características de principios del presente siglo, transitaron de la mano con la aparición de la subjetividad como problema propio de la 
filosofía y de las ciencias sociales, así como por el devenir de la condición humana hacia estadios inciertos de supervivencia, existencia y trabajo.

El filósofo surcoreano Byung-Chul Han reflexiona acerca de la autoexplotación actual a la que el individuo accede en búsqueda de su realización personal como parte de los valores y metas a alcanzar dentro de una sociedad global, hiperconsumista y altamente competitiva $(2012,72)$. Con base en este planteamiento se abre la reflexión sobre el trabajo o, mejor dicho, sobre cómo el trabajar permea la vida diaria de las personas que requieren de ello para sobrevivir en un mundo capitalista, sin embargo, dicha sobrevivencia, en sinfín de ocasiones, rebasa las necesidades materiales y las convierte en necesidades existenciales de tipo simbólico que se relacionan con los deseos de reconocimiento, poder, pero también de realización y felicidad.

¿Qué significa estar-en-el-mundo dentro de una sociedad capitalista hiperconsumista? ¿Cómo se replantea la condición humana a partir de una aceptación voluntaria de la explotación de sí, la renuncia a la vida privada y la búsqueda de la riqueza como fin en sí mismo? (2003). Hasta el día de hoy, la relación entre trabajo y capital continúa configurando la explotación del medio ambiente, la organización de los grupos sociales y los modos de existencia, entre otras cosas, estableciendo con ello el marco 
de valores desde los que se juzga la vida, las relaciones y los modos de ser y existir.

Sin embargo, el diagnóstico de Byung-Chul Han (2012) devela a una sociedad cansada, contrariada y enferma, cuya búsqueda concentrada en cumplir las metas y las expectativas capitalistas la alejan, paradójicamente, del modelo de sociedad hedonista que persigue. En este sentido, la existencia de las subjetividades producidas bajo regímenes neoliberales y sus nuevos estadios capitalistas parecieran resumirse en subjetividades que están en el mundo para trabajar.

La relación contradictoria entre trabajo y existencia no es característica exclusiva de las sociedades actuales. El fetichismo económico junto con la utilidad y la idea de progreso se han entrelazado constantemente como fines inmanentes de la producción y acumulación capitalista. La instrumentalización del conocimiento, la ciencia, el arte, la educación, entre otros campos, continúa permeando la generación, producción y divulgación de estos, y colonizando cada espacio de la existencia a favor de una reproducción de las relaciones capitalistas y la acumulación de capital. El reto marxista para transformar la realidad, más allá de la observación, descripción, diagnóstico y explicación de ésta exige al quehacer filosófico la ejecución de una teopraxis que rebase las paredes de los centros académicos y que se materialice en el estar concreto de la vida cotidiana. 
Las razones fundamentales de nuestra existencia demandan ser replanteadas, pero no sin reconocer nuestro habitar en el mundo, así como la imposibilidad de sustraernos de nuestras condiciones materiales, históricas, culturales y sociales que envuelven nuestra existencia. Pues la falacia del regreso al individuo, a la voluntad individual, conduce hacia una apuesta solipsista en la que el principal -y casi siempre- perdedor es el individuo que intenta comprender la complejidad del sistema y usarla a su favor desde la capacidad de desplegar un espíritu emprendedor.

El fundamento ontológico de la existencia, en el despegar del siglo XXI, requiere, paradójicamente, una ontología no centrada en la subjetividad pura, sino en su relación con el mundo, las instituciones, la historia, la economía, la política, la cultura y, sobre todo, su relación con los otros. Así, la pregunta sobre sí, sobre el ser-en-elmundo y sobre la finalidad de nuestras acciones podrían plantearse no sólo en un "por qué», sino en un «para qué» arraigado y posicionado en la condición particular de la existencia subjetiva.

La eliminación de la experiencia inmediata de la subjetividad se vuelve una consecuencia, deseada o no, de la producción capitalista que requiere más que subjetividades a individuos capaces de encajarse en el sistema de manera voluntaria, alienándose de su experiencia concreta del mundo y, a su vez, perdiendo la experiencia del tiempo de larga duración desde la 
inmediatez del tiempo presente y el constante flujo de mercancías, experiencias, placeres e incluso de la vida misma.

El reto de transformación del mundo hacia uno más justo y equitativo está aún pendiente, pero también lo está la emancipación del sujeto respecto de aquello que, como el trabajo, lo aliena de su propia experiencia subjetiva del mundo. El trabajo y la condición humana han ido de la mano durante miles de años (Engels, 2001), por lo que es probable que en estos tiempos de capitalismo exacerbado lo que somos esté relacionado con el marco de consumo que posibilita la remuneración de nuestro trabajo. Sin embargo, en otro tiempo, en un tiempo discontinuo, en un tiempo que no sigue la lógica del capitalismo quizá sea posible la experiencia llena y placentera de la existencia de la subjetividad. Quizá la pregunta inmediata para el individuo de a pie no es cómo destruir al sistema, sino cómo hacer florecer la subjetividad desde una experiencia concreta del mundo que incluye el trabajo como condición para la supervivencia.

\section{El capitalismo actual y sus marcos de subjetivación}

En el auge del capitalismo durante el siglo XIX comenzaron a gestarse nuevas formas de subjetivación singulares $y$ 
colectivas que hicieron florecer en el siguiente siglo a un sujeto que no había tenido lugar ni en el estado de cosas que configuran lo social, como tampoco en la plataforma del conocimiento (2014). El sujeto asalariado y libre, propio del capitalismo, en el presente siglo XXI, muestra un estado de marchitamiento dado por el camino que ha recorrido junto con el devenir de aquel, manifestando que algo no funciona existencialmente bajo las demandas neoliberales y sus consecuentes fases.

Las condiciones laborales cada vez más alejadas de los ideales de las luchas obreras de los pasados siglos, de la mano con las actitudes proactivas del emprendedurismo, arrojan al individuo hacia un estado solitario y romántico capitalista, en el que el pequeño sujeto ya no se enfrenta sólo a la naturaleza inconmensurable, sino al sistema tempestuoso que, a pesar de no proporcionar de manera equitativa las condiciones básicas, le demanda ser responsable de sí, de su cuidado y de su supervivencia.

Así, entre la pobreza y la marginación frente a la sobreabundancia de mercancías, para los que no son ni pobres ni ricos, recordando a Žižek (2010; 23) en la indefinición de la clase media, el éxito y la realización personal se concentran en la cantidad de mercancías que son capaces de adquirir. En un mundo en que el capital es una relación y todo está mediado por éste, las relaciones con los otros y con uno mismo quedan determinadas por los lugares que visitamos, las mercancías que nos visten o que 
adornan nuestros hogares, los alimentos que consumimos, los tratamientos estéticos que nos aplicamos, o lo que, al contrario, no consumimos. Todas estas mercancías, la «mercancianización» de la vida, enmarcan con quiénes nos relacionamos y con quiénes no, así como la imagen que construimos de nosotros mismos desde la experiencia de nuestra propia subjetividad, y ante la comunidad de los otros a partir de los cuales que me reconozco y, en parte, me defino como ser humano.

En esta comunidad global de realización personal y éxito profesional, las relaciones de poder se reconfiguran hacia la exigencia personal y la autoexplotación. Como Byung-Chul Han (2012; 45) menciona, la vigilancia y disciplina ya no están concentradas en la figura de un amo/jefe/patrón que observe nuestra eficiencia, sino que para estas «filosofías» del coaching, del «secreto», entre otras, la clave consiste en la eliminación de la palabra (y la actitud) víctima del vocabulario del «ganador», para pasar a tomar completa responsabilidad de las condiciones individuales. No obstante, es necesario resaltar que estamos hablando de las condiciones de vida del individuo, y no de sus acciones. En las ciencias sociales, por ejemplo, el dilema común de la relación entre el individuo y lo social que deriva en la pregunta sobre la posibilidad de un cambio social originado por el individuo, se enfrenta con el dilema existencial entre la responsabilidad de sí y la desigualdad concreta, material y simbólica existente entre cada uno de 
los sujetos individuales y el lugar que ocupan en el tejido social.

La meritocracia supone que cada quien es responsable de conseguir o no una movilidad social, ignorando la desigualdad de las condiciones sociales desde las que se parte. Así, en este diálogo contradictorio de la sociedad capitalista, siempre existe el contraejemplo a las críticas del sistema que ilustra cómo algún individuo cuyas condiciones sociales eran paupérrimas: pobreza, segregación, enfermedad, etcétera, y que ha logrado sobreponerse y rebasar sus condiciones sociales y alcanzar una movilidad que lo ha llevado a ocupar un lugar opuesto al que tenía anteriormente. El ejemplo confirma la sentencia: «si quieres obtener lo que pocos tienen, debes estar dispuesto a hacer lo que pocos hacen». Es por ello que, si no has alcanzado una estabilidad económica, o si eres pobre o si no «triunfaste», dentro de un sistema capitalista neoliberal, la culpa es tuya: pues no te esforzaste lo suficiente o no estuviste dispuesto a sobrexplotarte, dejando de lado a las condiciones meso y macroestructurales como la inflación, el desempleo, la violencia, la guerra o el cambio climático que provocan, cada una y en conjunto, el desplazamiento de miles de personas y el desclasamiento de familias particulares.

Frente al panorama actual de incertidumbre política, económica y social se requiere replantear el devenir al que se enfrenta la condición humana del capitalismo tardío, y a las subjetividades concretas que nos producimos en éste. 
Sin embargo, no se trata de ponerse la tarea de experimentar a la subjetividad pura (2011), sino de reconocer que habitamos en el mundo como seres finitos determinados por las condiciones materiales, históricas, culturales y sociales. En la sobrevaloración del individualismo, la falacia consiste en hacer recaer en el individuo singular el destino del devenir social en lugar de comprender el funcionamiento de los determinismos sociales, en promocionar la competencia y la fragmentación en lugar de encontrar la forma de generar comunidades políticas que confronten la aparente inmovilidad de la estructura social y la desigualdad (2005), y en defender la neutralidad de lo políticamente correcto en lugar de comprender la contradicción que evidencian los testimonios de los pobres, de los desplazados y de los desaparecidos.

\section{La producción de la subjetividad y el individuo emprendedor}

Al venir al mundo nuestra estancia en éste queda enmarcada por una serie de a priori sociales e históricos que desbordan la pureza de la subjetividad. El lugar que ocupa nuestra familia o comunidad en el mundo social determinará si estaremos o no en el mundo trabajando. Para la mayoría de nosotros ese espacio social que hemos ocupado ha delimitado el capital económico, simbólico, 
educativo y social con el que contamos. Por lo que la forma en que producimos nuestros bienes no estará muy alejada de la suma de capitales que sostienen la reproducción de nuestra vida.

El trabajo y el tipo de trabajo que realizamos conducen hacia experiencias existenciales concretas a partir de las que nos relacionamos directamente con el mundo. Sin embargo, como bien ilustra Bread and Roses de Ken Loach (2001): trabajamos porque queremos pan, pero también queremos rosas, reducir la relación de las singularidades subjetivas en un mundo capitalista al análisis desde la enajenación en el trabajo y el fetichismo de la mercancía restringe la complejidad de la condición humana a la reproducción de la vida orgánica. En esta contradicción o en esta complejidad, Byung-Chul Han (2012) diagnostica subjetividades cansadas y enfermas que buscan satisfacer necesidades aparentemente personales que el mundo capitalista impone a los modos de ser. No obstante, el consumo de mercancías como la música, los libros, el cine, los alimentos, entre otras cosas, también nos conduce hacia la producción de la subjetividad desde un espacio-tiempo que puede poner en pausa la lógica y el ritmo del capitalismo.

Así, entre el placer y el tedio, nuestra vida deambula del trabajo al tiempo libre que nos queda para descansar y distraernos de aquel, para poder regresar una vez concluido dicho tiempo. Entre el placer y el tedio nuestras 
subjetividades se producen a partir del trabajo, como señala Byung-Chul Han (2012) sobre la necesidad de medicarse para responder a la vida activa de la cotidianidad. Entre el exceso de cafeína y los antidepresivos nuestra existencia se sostiene para tener tiempo de disfrutar de ella. La actualidad deambula entre las categorías pseudosociológicas de los millenials que dedican sus esfuerzos a viajar y conocerse a sí mismos, y los centenialls o las nuevas generaciones que a los 5 años ya tienen un CV propio en el que demuestran sus competencias, habilidades y conocimientos para poder ingresar al mejor Jardín de Niños de la ciudad, según la nota que se hizo viral en noviembre de 2018, sobre un niño de 5 años en China cuyo currículum se extendía en 15 páginas ${ }^{1}$.

Si bien el ser humano trabaja, a diferencia de los animales que reproducen su vida en lo inmediato, el trabajo ha pasado a ser no sólo una necesidad de reproducción de la vida, sino una condición de su existencia, por lo que es menester revisar el sentido que carga y la forma en que interactuamos con el mundo a través de éste, desde la experiencia del ser y su subjetividad.

${ }^{1}$ Mariño, D. (2018). Un niño de 5 años con 15 hojas de CV: la locura en China para los colegios de élite. De La información. Sitio web: https:/www.lainformacion.com/mundo/nino-5-anos15-hojas-cv-lalocura-china-entrar-colegios-elite-privados/6436571 


\section{La condición humana en el estado actual de capitalismo}

La contradicción existencial que nos produce el trabajo en la experiencia que tenemos sobre el mundo no es intrínsecamente exclusiva de las sociedades actuales. El régimen capitalista absolutiza a la utilidad, el consumo y la reproducción del capital como las únicas opciones válidas de reproducción de la vida, es decir, la producción de objetos y servicios que se puedan consumir y, por ende, activar la circulación de mercancías, parecen ser la única fórmula legítima de estar en el mundo. Ante la restructuración de las políticas educativas emparejadas a políticas neoliberales en las que la investigación pierde terreno ante la profesionalización, se pone de manifiesto que el conocimiento, el arte, la educación, entre otros, van siendo colonizados cada vez más por la instrumentalización de la razón y la optimización del tiempo libre.

El diálogo teopráctico marxista entre el conocimiento y la realidad, entre el sujeto y lo social, reclama su ejercicio concreto antes de que la totalidad de los derechos se conviertan en privilegios ante la crisis humanitaria mundial que precisamente deja sin la posibilidad de reproducir su vida a miles de personas y, por tanto, sin la posibilidad de preocuparse por su trabajo ni por su existencia.

Lejos de la búsqueda exclusiva por la realización individual, el sentido de comunidad debe replantearse y 
redefinirse desde la relación intersubjetiva que compartimos en el mundo capitalista. La pregunta por el «sí mismo» debe complementarse con la pregunta por el «para qué», abarcando a la existencia propia y poniendo entre corchetes los designios del capital, a la vez que se pone en consideración que los otros están en el mundo, al igual que el primero, trabajando.

Hacer florecer la subjetividad propia en el mundo del capitalismo actual es uno de los retos más difíciles a los que nos enfrentamos todos aquellos que dividimos nuestro tiempo inmediato entre trabajar y descansar. El régimen capitalista no necesita de individuos que generen subjetividades auténticas y desinteresadas del consumo, el éxito, el lujo, la fama, el poder, o el reconocimiento, pues le es prioritario reproducir individuos $y$ colectividades dispuestos a encajar en el sistema de manera voluntaria, alienándose de la experiencia de su subjetividad en el mundo y reproduciendo su existencia entre el consumo de mercancías y la realización del trabajo que permite consumir esas mercancías.

\section{Bibliografía}

Han, B-Ch. (2012). La sociedad del cansancio, Arantzazu Saratxaga (trad.). Barcelona: Herder. 
Heidegger, M. (2003). Introducción a la metafísica. Angela Ackermann (trad.). México: Gedisa.

Moran, D. (2011). Introducción a la fenomenología, Pablo Fernando Lazo y Francisco Castro (trad.). Barcelona: Anthropos.

Engels, F. (2001). El papel del trabajo en la transformación del mono en hombre. México: Ediciones Quinto Sol.

Foucault, M. (2014). Las palabras y las cosas, Elsa Cecilia Frost (trad.). México: Siglo XXI.

Rancière, J. (2005). Sobre politicas estéticas, Manuel Arranz (trad.). Barcelona: Museu d'Art Contemporani de Barcelona, Servei de Publicacions de la Universitat Autónoma de Barcelona.

Žižek, S. (2010). En defensa de la intolerancia, Javier Eraso Ceballos y Antonio Antón Fernández (trad.). España: Diario Público. 